\title{
A FUNÇÃO DA VOGAL EPENTÉTICA NA CONSTRUÇÃO DA SÍLABA $C V^{1}$
}

Edson de Freitas GOMES ${ }^{2}$

Campus Universitário de Abaetetuba/UFPA

edsongomes@ufpa.br

Resumo: Este artigo tem o propósito de mostrar a ocorrência da epêntese em palavras faladas por 16 (dezesseis) informantes do bairro do Mutirão e da comunidade do Ipixuna, em Abaetetuba-Pará, levando-se em consideração fatores socioculturais, tais como gênero, idade e escolaridade, que influenciam o modo de vida das pessoas, bem como os atos linguísticos. As gravações foram feitas em gravador digital Linear PCM Recorder LS-10, a partir de um corpus composto por 8 (oito) palavras da lingua portuguesa. Depois de coletados, os dados foram analisados, a fim de se obter um resultado dessa análise.

Palavras-chave: Epêntese. Vogal alta. Vogal média alta.

Abstract: This article aims to show the occurrence of epenthesis in words spoken by (16) sixteen informants in the neighborhood of Mutirão and community Ipixuna Abaetetuba-Pará, taking into consideration sociocultural factors such as gender, age and education, that influences the way of life and also acts language. The recordings were made using a digital recorder Linear PCM Recorder LS-10, from a corpus of 8 (eight) words of Portuguese. Once collected, data were analyzed in order to obtain a result of these.

Keywords: Epenthesis. High vowel. Vowel high average.

\section{Introdução}

A epêntese é um fenômeno que vem se tornando uma característica dos falantes do português brasileiro. Por isso é importante desenvolver pesquisas com maior profundidade sobre o fenômeno, a fim de conhecêlo e dominá-lo melhor, e para que possamos dispor de material escrito para futuras pesquisas, haja vista ser a epêntese muito utilizada devido ao significativo número de palavras em que ela ocorre.

${ }^{1}$ Consoante Vogal.

${ }^{2}$ Técnico-Administrativo da UFPA e Mestre em linguística pela Universidade Federal do Pará. 
O objetivo deste trabalho é verificar com que regularidade ocorre o fenômeno da epêntese nas palavras utilizadas na fala dos moradores do bairro do Mutirão e da comunidade do Ipixuna, no município de Abaetetuba-Pará e qual é a vogal mais utilizada para formar o núcleo da sílaba nestas palavras, se a vogal alta $\mathbf{I}$ ou a vogal média alta $\mathbf{E}$.

Inicialmente, construímos um referencial teórico que aborda a epêntese, com o fito de embasarmos o trabalho, a partir da visão de alguns autores, em material escrito que tratam do fenômeno. A metodologia nos mostra quais os passos que devemos seguir para a construção do trabalho, o qual inclui pesquisa de campo, em que são levados em consideração fatores socioculturais. O corpus do trabalho está composto pelas palavras que foram utilizadas com os informantes durante as entrevistas.

Posteriormente, apresentamos a análise dos dados coletados, os quais apresentam como resultado uma pequena amostra do uso da epêntese pelos informantes do bairro do Mutirão e da comunidade do Ipixuna. Em seguida, concluímos com os comentários feitos sobre os resultados obtidos. Finalmente, temos as referências bibliográficas, que fazem parte de um conjunto de obras que abordam a epêntese.

\section{O Fenômeno da Epêntese}

A vogal epentética ocorre entre duas consoantes não líquidas. De uma forma CC (Consoante-Consoante) passa-se a outra forma CVC (Consoante-Vogal-Consoante). No caso do Português brasileiro, entre as consoantes é emitida a vogal alta /i/. Segundo Parlato-Oliveira (2005), "A língua portuguesa brasileira apresenta o fenômeno de epêntese perceptual com a inserção da vogal /i/. [...] a epêntese perceptual é um fenômeno fonético e não o resultado de propriedades ortográficas, lexicais ou gramaticais da língua."

A epêntese vocálica tem como objetivo principal corrigir uma estrutura vocálica mal formada, fazendo com que certas consoantes que ocupavam a posição de coda ${ }^{1}$ passem-na para a posição de onset ${ }^{2}$, dando um núcleo vocálico a uma sílaba que não o tem ou formando ditongos.

$\overline{{ }^{2} \text { Consoante localizada no final da sílaba. }}$

${ }^{3}$ Consoante localizada no início da sílaba. 
Hora et al (2009, p. 76) diz que "algumas línguas apresentam codas com comportamentos diferenciados, dependendo de sua posição, se interna ou final. Além de apresentar a inserção de uma vogal, transformando a coda em onset.", conforme mostrado no esquema abaixo.

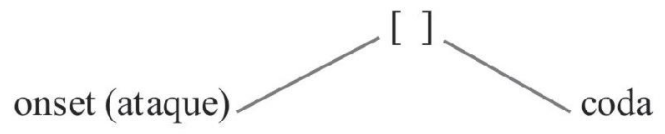

Consoante

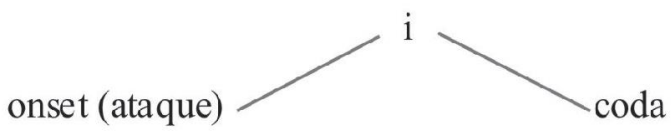

Consoante

A seguir apresentamos a seguinte representação para silabação da primeira sílaba da palavra pneu ${ }^{\square}$.

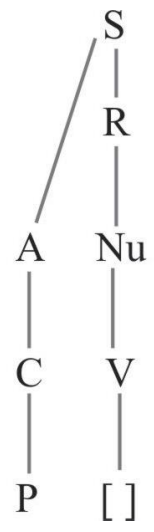

Na representação, o P indica o traço da consoante e o colchete indica a posição vazia do núcleo da sílaba, que é preenchido com a epêntese.

Collischonn (2003, p. 21) assim descreve a epêntese:

[...] a epêntese ocorreria ainda no componente lexical da fonologia do português brasileiro, como resultado do

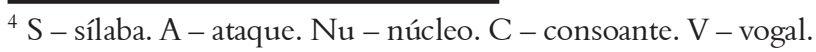


processo de silabação. Durante a silabação, uma consoante não apta a ocupar uma posição silábica de ataque ou coda permaneceria não ligada a nenhum nó silábico (chamamos essa consoante de consoante perdida). A existência de uma dessas consoantes perdidas na representação fonológica desencadearia a criação de uma sílaba estrutural, desprovida ainda de núcleo vocálico, mas a qual permite a associação da consoante perdida em posição de ataque [...].

Há que se considerar que os brasileiros, ao aprenderem o inglês como língua estrangeira, fazem uso de uma vogal como estratégia para a formação de sílabas. Nas formas 'stop' [Iztop] > [Iztopi]; 'fish' [fIJ] > [ $\left.\mathrm{f}_{\mathrm{I}} \mathrm{j}\right]$, por exemplo.

Para Bisol apud (Neves, 1999, p. 730), "A vogal epentética realizase o mais das vezes como [i], ocorrendo também [e], em alguns dialetos, mas somente em posição pretônica, como em futebol, peneu ou peneumonia, todas com a alternante de vogal alta: futibol, pineu, pineumonia."

Esse é o caso mais frequente de epêntese, porém, no nível da flexão, podemos encontrá-la em palavras que terminam em $\mathbf{R}$ ou $\mathbf{L}$ e que no plural se acrescenta $\mathbf{S}$. Segundo Bisol, quando o $\mathbf{S}$ aparece em posição de coda é sinal de que se pode desenvolver uma vogal epentética. Podemos usar como exemplo as palavras mar e mal do português, e a palavra dólar do inglês.

$$
\begin{aligned}
& \text { mar }>\text { mars }>\text { marVs }>\text { mares } \\
& \text { mal }>\text { mals }>\text { malVs }>\text { males } \\
& \text { dólar }>\text { dolars }>\text { dolarVs }>\text { dólares }
\end{aligned}
$$

No português brasileiro, a epêntese vem se tornando um fenômeno recorrente, devido ao uso frequente do fonema/i/ nas posições interna, final e inicial. No caso da epêntese inicial, a ocorrência está relacionada à proibição, tanto do português como de algumas línguas romanas, do ataque inicial de s+obstruinte, herança recebida do latim. Como exemplo, temos as palavras: istrela (estrela), ispaço (espaço) e istranho (estranho).

Trabalhamos nesse artigo com a hipótese de que encontraremos, nas falas dos entrevistados, registros que estão relacionados à idade e à escolaridade dos informantes, como no uso da palavra "advogado", 
que é muito falada pelas pessoas com idade mais elevada e de baixa escolaridade, no município de Abaetetuba, usando a vogal epentética, média alta e, o que faz com que tenhamos adEvogado. Outro exemplo que podemos citar é a palavra "pneu", em que é recorrente o uso da forma com a vogal média alta $\mathbf{e}$, independentemente de idade e escolaridade, resultando em pEneu. Estas palavras, quando recebem o e epentético é porque o fenômeno acontece na palavra em posição pretônica.

\section{Metodologia}

Para a realização do trabalho, foram selecionados 16 informantes das zonas urbana e rural do município de Abaetetuba-Pará. A localidade da zona urbana é o bairro do Mutirão, e a da zona rural é a comunidade do Ipixuna. Foram levados em consideração fatores extralinguísticos, como sexo, idade e escolaridade, sendo oito informantes da zona urbana e oito informantes da zona rural. Dos 16 informantes, oito são homens e oito são mulheres. A faixa etária selecionada foi oito informantes de 18 a 30 anos e oito informantes de 40 a 70 anos. A escolaridade exigida foi a seguinte: oito informantes que houvessem cursado até a $4^{\mathrm{a}}$ série do Ensino Fundamental, e oito informantes que tivessem o Ensino Médio completo. As gravações foram feitas em gravador digital Linear PCM Recorder LS-10, a partir da aplicação de um questionário composto por oito palavras que fazem uso da vogal epentética.

Ao selecionarmos as oito palavras para serem pronunciadas pelos informantes, levamos em consideração o grau de dificuldade que estes teriam para proferir algumas delas, por serem difíceis de contextualizálas. Por isso só utilizamos palavras que apresentariam o menor grau de dificuldade para a pronúncia dos informantes, razão pela qual tivemos que deixar de fora do questionário muitas outras palavras que apresentam a epêntese. Neste trabalho, adotamos os termos utilizados por Silva (2005): vogal alta anterior não-arredondada para o i, e vogal média alta anterior não-arredondada para o e.

As 16 gravações foram realizadas nos dias 18 e 19 de novembro de 2011. O tempo total das gravações foi de 29 minutos e 33 segundos. 


\subsection{Corpus}

O corpus do trabalho está constituído por oito palavras da Língua Portuguesa, nas quais verificaremos a ocorrência do fenômeno da epêntese. Examinaremos também em qual vogal das palavras que foram apresentadas há mais ocorrências desse fenômeno por ocasião da pronúncia dos entrevistados, se a vogal alta i ou se a vogal média alta e. As palavras selecionadas para o questionário foram as seguintes: abdômen, absorvente, adquirir, advogado, objetivo, objeto, pneu, psicólogo.

\subsection{Análise dos dados}

A seguir, apresentamos os dados das entrevistas coletadas, em forma de tabelas, para que possamos visualizar melhor o fenômeno da epêntese, o que deverá facilitar a compreensão.

\begin{tabular}{|c|c|c|}
\hline Palavras & Uso da vogal I & Uso da vogal $\mathbf{E}$ \\
\hline Abdômen & 16 informantes & \\
\hline Absorvente & 16 informantes & \\
\hline Adquirir & 16 informantes & \\
\hline Objetivo & 16 informantes & \\
\hline Objeto & 16 informantes & \\
\hline Porcentagem & $100 \%$ & \\
\hline
\end{tabular}

Tabela 1

As palavras da tabela 1: abdômen, absorvente, adquirir, objetivo e objeto foram faladas por todos os informantes com o uso da vogal alta i, 100\% de registros, o que resultou em abIdômen, abIsorvente, adIquirir, obIjetivo e obIjeto. $\mathrm{O}$ resultado mostrou-nos que a epêntese nessas palavras se dá com a vogal $\mathbf{i}$, independentemente de faixa etária, sexo e escolaridade dos informantes. Os dados nos mostraram que as formas usadas pelos falantes foram aquelas que se ouve com maior 
frequência nas localidades objeto da pesquisa. Por outro lado, nenhum dos informantes usou a vogal e nas cinco palavras objeto da entrevista, o que de certa forma confirma a nossa suposição de que não é comum as pessoas fazerem uso dessa vogal cotidianamente ao pronunciarem essas palavras.

\begin{tabular}{|c|c|c|}
\hline Palavra & Uso da vogal I & Uso da vogal E \\
\hline Advogado & 14 informantes & 02 informantes \\
\hline Porcentagem & $87,5 \%$ & $12,5 \%$ \\
\hline
\end{tabular}

Tabela 2

A palavra da tabela 2 , advogado, foi falada por 14 dos 16 informantes com o uso da vogal alta $\mathbf{i}$, resultando na forma adIvogado, o que representa $87,5 \%$ de ocorrência. Apenas dois informantes pronunciaram a palavra com a vogal média alta e, resultando na forma adEvogado, que representa $12,5 \%$ de registros. Esses dois informantes estão na faixa etária de 40 a 70 anos e cursaram até a $4^{\mathrm{a}}$ série do Ensino Fundamental. Esse resultado vai de encontro a nossa hipótese inicial, que seria a de encontrar o registro de aproximadamente quatro informantes fazendo uso desse registro da palavra, por acreditarmos que os informantes mais velhos e com menor escolaridade falariam a palavra advogado com a vogal e; e havia quatro informantes com essas características, porém apenas dois pronunciaram a palavra dessa forma.

\begin{tabular}{|c|c|c|}
\hline Palavra & Uso da vogal I & Uso da vogal E \\
\hline Pneu & 12 informantes & 04 informantes \\
\hline Porcentagem & $75 \%$ & $25 \%$ \\
\hline
\end{tabular}

Tabela 3

$\mathrm{Na}$ tabela 3, temos a palavra "pneu", que foi falada por 12 dos 16 informantes com o uso da vogal alta i, e, como resultado, tivemos pIneu, o que representa uma porcentagem de $75 \%$. Quatro dos informantes falaram a palavra do questionário com a vogal média alta e, o que resultou 
na palavra pEneu. Esse número representa $25 \%$ dos informantes. A ocorrência predominante da forma pIneu, $75 \%$, causou-nos certa surpresa, pelo fato de termos observado, antes deste trabalho, que as pessoas do município e entorno faziam uso com bastante frequência da forma pEneu, independentemente da idade e da escolaridade. Esse resultado nos levou a acreditar que os informantes talvez tenham optado por essa forma por desejarem falar "corretamente" ou mais elegantemente, pois essa não parece ser a realidade desses falantes, ou seja, não nos parece que seja comum o uso dessa forma por aquelas pessoas. Os informantes, predominantemente, serem originários de outro município e moram em locais em que a forma pEneu é largamente usada.

\begin{tabular}{|c|c|c|}
\hline Palavra & Uso da vogal I & Uso da vogal $\mathbf{E}$ \\
\hline & 15 informantes & 01 informante \\
\hline Porcentagem & $\square \square \square$ & $\square \square \square$ \\
\hline
\end{tabular}

Tabela 4

Por último, temos na tabela 4, a palavra "psicólogo" que foi falada por 15 dos 16 informantes usando a vogal alta i, 93,75\%, resultando na forma pIsicólogo. Apenas um informante falou com a vogal média alta e, representando 6,25\%, que resultou em pEsicólogo. Essa pronúncia nos causou também surpresa, porque não esperávamos o registro da palavra com a vogal e. Principalmente porque o informante compõe o grupo das pessoas com maior escolaridade, cuja expectativa mais provável seria falar pIsicólogo, assim como os demais.

\begin{tabular}{|c|c|c|c|}
\hline Advogado & Mutirão & Ipixuna & Porcentagem \\
\hline adIvogado & 7 informantes & 7 informantes & $87,5 \%$ \\
\hline adEvogado & 1 informante & 1 informante & $12,5 \%$ \\
\hline
\end{tabular}

Tabela 5

$\mathrm{Na}$ tabela 5, fazemos um quadro comparativo entre a epêntese na palavra advogado nas localidades objeto do estudo, Mutirão e Ipixuna, considerando a ocorrência da epêntese com a vogal alta $\mathbf{i}$ e com a vogal 
média alta e. A porcentagem foi calculada sobre a quantidade total de informantes nas duas localidades. Como podemos constatar, dos 16 informantes, apenas dois falaram a palavra advogado, fazendo a epêntese e, o que dá uma porcentagem de $12,5 \%$, resultado muito aquém da expectativa de ambas as localidades, para esse registro. As duas localidades registraram o mesmo número de ocorrências. $\mathrm{O}$ esperado seria que os oito informantes com baixa escolaridade falassem adEvogado, mas é adIvogado que aparece em $87,5 \%$ dos registros.

\begin{tabular}{|c|c|c|c|}
\hline Pneu & pIneu & pEneu & Porcentagem \\
\hline Mutirão & 5 informantes & 3 informantes & $37,5 \%$ \\
\hline Ipixuna & 7 informantes & 1 informante & $12,5 \%$ \\
\hline
\end{tabular}

Tabela 6

Na tabela 6, mostramos a porcentagem de uso da vogal média alta e em relação à vogal alta i. Podemos observar que dos oito informantes do Mutirão, três usaram a vogal média alta na epêntese, $37,5 \%$, resultado que mais se aproxima do esperado, considerando a hipótese de que é comum no município a expressão pEneu. Já no Ipixuna, a ocorrência foi ainda mais discreta, apenas um informante, 12,5, usou a vogal média alta. Esse resultado foi muito diferente do esperado, por se tratar de uma localidade da zona rural de Abaetetuba que apresenta a possibilidade maior de ocorrência de pEneu.

\begin{tabular}{|c|c|c|}
\hline Mutirão & pIneu & pEneu \\
\hline Homem $18-30$ & $\mathrm{X}$ & \\
\hline Homem $40-70$ & & $\mathrm{X}$ \\
\hline
\end{tabular}

Tabela 7

Na tabela 7 , em relação à palavra pneu, houve diferença entre os informantes homens, do Mutirão, quanto ao fator idade, haja vista que os dois informantes mais jovens pronunciaram pIneu, enquanto que os dois mais velhos pronunciaram pEneu. Nesse caso, houve diferença 
de registro da palavra quando se tratou de informantes com idades maiores.

\section{Conclusão}

Concluímos este trabalho com a certeza de que a utilização da vogal epentética na modalidade oral é muito comum entre os falantes do português brasileiro. Foi possível constatarmos que, embora pensemos que estamos certos de que determinados falantes fazem uso de palavras em certa perspectiva, no momento em que colhemos os dados desse falante podemos nos surpreender com o resultado obtido, porque a expectativa pode não se confirmar. Neste trabalho tivemos a oportunidade de perceber isso.

No caso da palavra advogado, por exemplo, esperávamos que os entrevistados mais velhos e com menor escolaridade falassem-na adEvogado, mas apenas a metade deste grupo de entrevistados confirmou o esperado. Assim como a palavra pneu, que a expectativa seria que todos ou a maioria dos 16 informantes falassem $\mathrm{pEneu}$, mas somente quatro informantes, $25 \%$ corresponderam ao esperado.

Na comparação da pronúncia da palavra pneu nas duas localidades pesquisadas, houve de certa forma uma inversão do resultado esperado, porque no bairro do Mutirão, que fica na zona urbana, esperávamos que a pronúncia pIneu fosse a mais comum. Mas foi em Ipixuna, que fica na zona rural, que obtivemos mais registros dessa forma, ou seja, é nessa localidade que os informantes mais usam a vogal alta $\mathbf{i}$.

Assim, nos foi possível constatar que nem sempre será na cidade que encontraremos o registro de pronúncias mais próximo da chamada norma-padrão, de maior prestígio, como podemos observar no parágrafo acima, no exemplo da palavra pneu. Já com a palavra advogado, obtivemos o número de registros igual nas duas localidades, tanto com a vogal alta, como com a vogal média alta.

\section{REFERÊNCIAS}

BISOL, Leda. A sílaba e seus constituintes. In: NEVES, Maria Helena de Moura (Org.). Gramática do português falado volume VII: novos estudos. Campinas: Editora da Unicamp, 1999. 
COLLISCHONN, Gisela. Epêntese vocálica no português do Sul do Brasil: variáveis extralinguísticas. Anais do $5^{\circ}$ Encontro do Celsul, Curitiba, 2003, p. 21-27.

CONDURÚ, Marise Teles; PEREIRA, José Almir Rodrigues. Elaboração de trabalhos acadêmicos: normas, critérios e procedimentos. $4^{\mathrm{a}}$ ed. Belém: 2010.

HORA, Demerval da; LUCENA, Rubens Marques de; PEDROSA, Juliene Lopes R. A inserção vocálica após a coda silábica: uma abordagem variacionista. In: HORA, Demerval da (Org.). Vogais: no ponto mais oriental das Américas. João Pessoa: Ideia, 2009.

PARLATO-OLIVEIRA, Erika. Análise acústica da vogal epentética da língua portuguesa brasileira. In: HORA, Demerval da (Org.). Vogais: no ponto mais oriental das Américas. João Pessoa: Ideia, 2009.

SILVA, Thais Cristófaro. Fonética e fonologia do português: roteiro de estudos e guia de exercícios. $8^{\mathrm{a}}$ ed. São Paulo: Contexto, 2005.

SIMÕES, Darcilia Marindir Pinto. Considerações sobre a fala e a escrita: fonologia em nova chave. São Paulo: Parábola, 2006. 